height of the $E$-layer was found to be $135 \mathrm{~km}$. and usually four multiple reflections and sometimes as many as six were detected. Between 19.00 and 19.30 I.S.T., the intensity of the first reflection often shot up to 2-3 times that of the ground wave, but this unusual intensity lasted for about 3-5 seconds. Between 19.15 and 19.20, the intensity of the second reflection was found on two occasions to be from 3 to 4 times that of the ground pulse, although the intensity of the first reflection was only about half that of the ground pulse.

Further observations were taken in the early morning hours (5.30-6.30) of May 14. The beight of the $F$-layer was found to be $270 \mathrm{~km}$. in the beginning and gradually fell to $250 \mathrm{~km}$. Four reflections were usually present; the first was always the strongest, its intensity sometimes becoming as great as that of the ground pulse.

The distance between the adjacent reflections was always the same, thus showing the presence of multiple reflections between the earth and the ionosphere. Messrs. Mitra and Rakshit ${ }^{2}$ could detect the multiple reflections one hour before the sunset, but we have been able to observe multiple reflections in the morning as well.

It appears from our observations that the $E$-layer is predominant during the evening and sunset period, and during the night the ionisation in the lower layer becomes too small, and up to about half an hour after sunrise reflections from the $F$-layer are observed.

The work is being continued.

G. R. Toshniwal.

B. D. Pant.

Physical Laboratory,

Allahabad.

May 21.

Mitra and Rakshit, Phil. Mag., 15, 20; 1933.

loc. eit., p. 26.

\section{Effect of Thunderstorms upon the Ionosphere}

Morgantown, West Virginia, U.S.A., is situated on the western slope of the Appalachian Mountains, which run in a south-westerly direction. These mountains cause a great deal of variation in the signal strength of the broadcasting stations along the Atlantic coast as received in Morgantown, and also affect the short-wave band.

One of my students, Mr. A. W. Friend, has been operating a short-wave station here for many years. $\mathrm{He}$ informs me that on account of the high hills near his home, his station cannot be heard in the southeastern sector of the United States except after $a$ thunderstorm. He can hear the amateur short-wave stations in the southern States, but they can never hear him if the weather is fine; but after a thunderstorm he can remain in contact with them for several hours.

At my suggestion, Mr. Friend made out the following table from the log of his station. It shows the times at which the stations were able to hear him.

\begin{tabular}{|c|c|c|c|c|}
\hline $\begin{array}{l}\text { Stati } \\
\text { treensbor } \\
\text { Vilmingto } \\
\text { Iarion, A }\end{array}$ & $\begin{array}{l}\text { Date } \\
\text { April 29, } 1931 \\
\text { April 30, 1931 } \\
\text { June 2, 1931 } \\
\text { June 5, 1931 } \\
\text { Aug. 24, } 1931\end{array}$ & $\begin{array}{c}\text { Time } \\
11.16 \text { p.m. } \\
6.15 \text { p.m. } \\
12.55 \text { a.m. } \\
10.38 \text { p.m. } \\
1.05 \text { a.m. }\end{array}$ & $\begin{array}{c}\text { Freq. Kc. } \\
7,000 \\
7,000 \\
7,000 \\
14,000 \\
7,000\end{array}$ & $\begin{array}{c}\text { Output, } \\
\text { watts } \\
12 \\
12 \\
12 \\
8 \\
15\end{array}$ \\
\hline
\end{tabular}

These stations are all located several hundred miles south or south-east of Morgantown, and two- way communication was never possible under normal atmospheric conditions. Mr. Friend's observations strongly support Prof. C. T. R. Wilson's theory that some of the ionisation in the ionosphere is due to thunderstorms. Not all of the abnormal ionisation arises, from local thunderstorms, for I have often observed increased ionisation in the $E$-layer after sunset during the winter months when there were no thunderstorms within a thousand miles.

Department of Physics,

R. C. Colwell.

West Virginia University. May 18.

\section{Static Charge on a Galvo-Millivoltmeter}

In Nature of May $19 \mathrm{Mr}$. H. A. Bromley mentioned the trouble he had experienced owing to the needle of a millivoltmeter being attracted by the electrostatic charge on the surface of the glass window of the instrument.

This trouble has been known for many years, and is usually overcome by wiping the glass with a cloth on which there is a slight trace of glycerine. This so effectually gets rid of the trouble for a little while -when the process has to be repeated-that I think readers of NATURE may be glad to know of it. ROBERT S. WhIPple. Cambridge Instrument Company, Limited,

45, Grosvenor Place, London, S.W.1.

\section{Velocity of Light}

THE chief objection which can be raised at the present time to the hypothesis of a continuous decrease of the velocity of light is that it is only justified if we admit that the work of Michelson and Newcomb in the last century is unreliable. Now, their determinations made in 1882 agree so closely, although made independently, with different instru. ments and a somewhat different technique, that, in my opinion, they are probably very accurate.

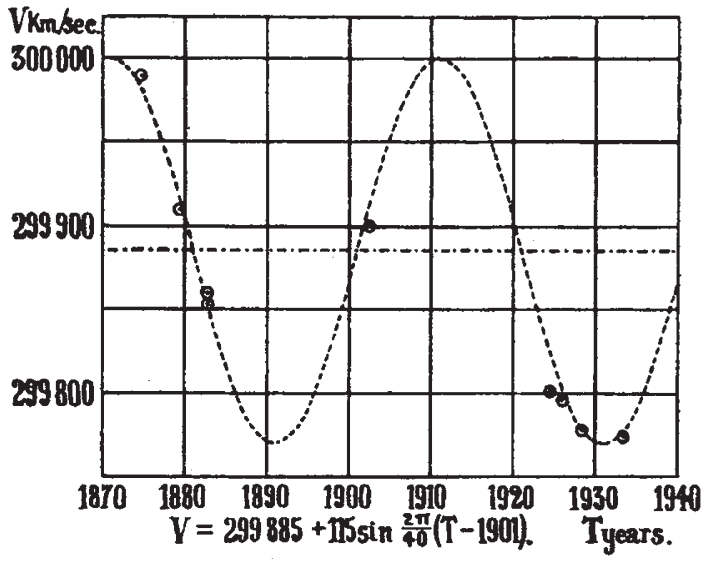

Fia. 1.

Seven years ago, I pointed out that the problem would be simplified if it were admitted that the velocity fluctuates ${ }^{1}$. The arbitrary rejection of some observations would not then be required, there having been a decrease in 1874-1883 and another in 19021934. An irregular variation, however, is of little scientific value : it is so easy to fit one to the observations; a regular, periodic variation, on the other 